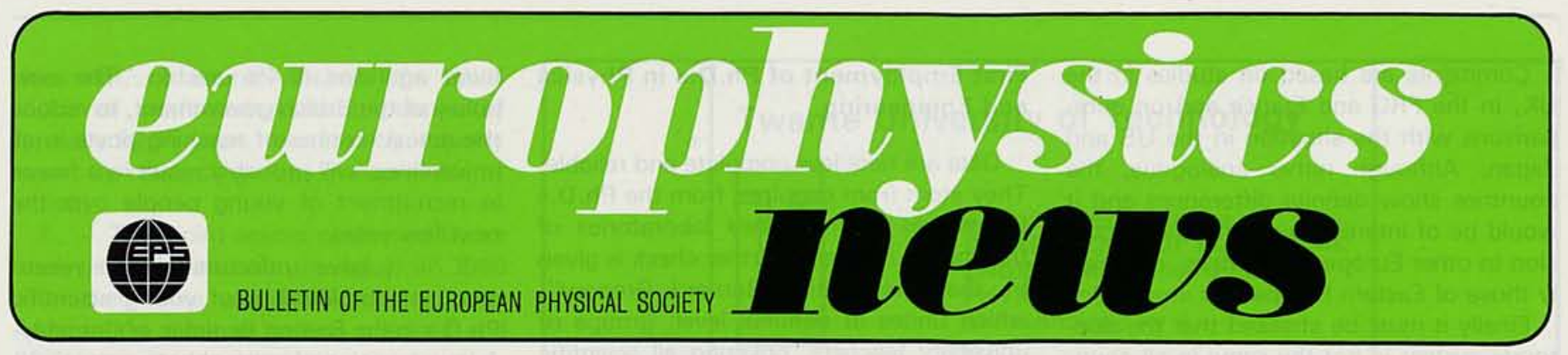

\section{Training and Jobs for Ph.D.s in Physics and Engineering}

\author{
J. Friedel, Orsay \\ President of the European Physical Society
}

The training of Ph.D.s, a function of the Universities but also a matter of social importance.
An essential function of the universities, according to tradition, is, through the various "doctorates", to train students to undertake research. This has been at the root of research in the universities in the 19 th and 20th centuries, and the reason for the dominance of the universities in fundamental research. In the post-war upsurge, the universities have tended to share this activity with research organisms and industrial laboratories, but they have usually kept a general control of the flux and quality of the Ph.D.s.

The scientific recession observed in many countries in the $70 \mathrm{~s}$ has often resulted in a general decrease in the numbers of Ph.D.s trained every year, both because there seemed to be fewer job openings for Ph.D.s in industry, government research careers looked less attractive. Often this has gone with a lowering of the tone of university research. In some countries however, a renewed demand for scientific Ph.D.s, especially in applied mathematics, physics, microelectronics and agencies and universities, and because the materials sciences, has developed in the last few years, and is often difficult to satisfy owing to a lack of Ph.D. students. This demand is primarily for research and development activities, at least as a starting point. But a certain number of jobs exist also in other areas, ranging from industry and commerce, to administration and secondary school teaching.

Both the training and employment of scientific Ph.D.s are therefore matters of the utmost importance to the laboratories that train them, their prospective users and through them, the whole social structure which can be permeated by the spirit of research.

Surprisingly there is little systematic study of this question as it develops from year to year, but I have been involved with the various efforts which have been made in France over the past five years, and it is my very limited knowledge of the problem which I relate here. Obviously this is a field where the EPS could be useful in collecting reliable data for physics from those European countries where they exist, in pro-
Table 1 - Ph.D.s Formed in Natural Sciences and Engineering

\begin{tabular}{l|c|c|c|c|c}
\hline Country & France & FRG & UK & USA & Japan ** \\
\hline Year & 1979 & 1978 & 1977 & 1978 & 1980 \\
\hline $\begin{array}{l}\text { Natural Sciences } \\
\text { (physics) }\end{array}$ & $\simeq 1700$ & 2463 & 2251 & 7385 & 681 \\
\hline Engineering & $\cong 350)$ & $(542)$ & $(412)$ & $(1066)$ & $(212)$ \\
\hline Total & $\simeq 800$ & 1042 & 939 & 2493 & 656 \\
\hline
\end{tabular}

NB * Splitting between physics and engineering is less marked than elsewhere.

** Exit fluxes of 3 year doctorate courses, not Ph.D.s, which on average take 4-5 years in science. moting their collection where they do not exist, in comparing them with data from other developed countries, and in drawing attention to possible mismatches, in quality as well as quantity, in the training and employment of Ph.D.s.

Two comments of caution should, however, be made from the start:

- The quantitative aspects upon which I shall concentrate are easier to gauge than the qualitative, whether these concern the formation of Ph.D.s or jobs offered, although the qualitative aspects are, of course, paramount in the long run.

- A better knowledge of the real situation can be helpful to students, university laboratories, organisms distributing Ph.D. grants and prospective employers. Long term planning however, so far has been shown to be inadequate, in both the overoptimistic period of university growth and in the over-depressed period of university saturation. In practice, the auto-regulation of the system has in most countries been better than expected, especially in physics, through a combination of the regulation of the flows and redoubled efforts to find new jobs to avoid unemployment. These efforts have been made essentially by the individuals concerned, with minimal help from national bodies. Awareness of this action at the "grassroots" level is essential.

\section{A Variety of Situations}

In what follows, I shall refer to scientific Ph.D.s only and those mostly in physics and engineering. Ph.D.s in life and human sciences present very specific and serious problems which will not be discussed here.

\section{Contents}

Training and Jobs for Ph.D.s in Physics and Engineering

Elementary Particle Physics Where is it Going?

Spotlight on Quantum Electronics and the Use of Dye Lasers

Reduced Subscriptions for Individual Members of EPS

New Members of EPS 
Comments are based on studies in the UK, in the FRG and France and on comparisons with the situation in the US and Japan. Although rather analogous, the countries show definite differences and it would be of interest to extend the discussion to other European countries, especially those of Eastern Europe.

Finally it must be stressed that the doctorate system is not the same in all countries. Roughly speaking, two types of organization prevail:

- a two level system, with a Ph.D. prepared typically in three years, before the age of 27 , and a second level taken typically four to eight years after, thus around 30-35, which opens the gates to university posts (and sometimes to higher positions in industrial research). This is the German system, with the "Doktorat" and the "Habilitation"; the French with the "Third Cycle" or "Ingénieur" theses and the "Doctorat ès Sciences"; the British, with the Ph.D. and the D.Sc.; the Russian with the "Candidate" and the "Doctorate" levels.

- a one level system, with a unique Ph.D. prepared typically in five years in science, and therefore passed at about 29-30 on the average. This is the American system, copied in the last fifteen years by a number of European countries (Scandinavia, Holland, Italy...) and in Japan.

So when referring to Ph.D.s it will be to the first grade of the first system, which I shall compare with the single grade of the second system.

\section{Flux of Ph.D.s Trained}

Table I compares the numbers of scientific Ph.D.s trained in five countries. These numbers are stable enough from year to year for a comparison to be valid despite differences in growth patterns. In the FRG and Japan, the yearly flow has regularly increased, and more than doubled since 1960 , whereas in the UK, France and the US, a decrease by about one quarter in the early '70s followed a similar growth in the '60s, with a stabilization over the past five years. In proportion of population, the numbers in Table I are roughly comparable, except for Japan, where more students stop at the bachelors or masters degree.

The training of women in scientific Ph.D.s is a fairly new development, especially in physics and engineering. The percentage yearly flux of (national) scientific Ph.D.s is low in Japan (3\%) and in the FRG $(7.5 \%$, purely in science); it is larger in the UK $(11 \%)$ and US $(15 \%)$ and especially in France (more than 25\%).

The percentage number of foreign Ph.D. students is apparently low in Japan, $11 \%$ for scientific Ph.D.s in Germany, to be compared with $20 \%$ for natural sciences and $45 \%$ for engineering in the US. France and the UK are in an intermediary position. Foreign students tend to be male.
First Employment of Ph.D.s in Physics and Engineering

Data are here less complete and reliable. They stem from enquiries from the Ph.D.s themselves or from their laboratories of training. In France, a further check is given by the "Association Bernard Gregory", which unites at national level, groups of university teachers, covering all scientific universities and major research organisms, who help to find jobs for Ph.D.s.

1. - In France, first employment for (national) physics Ph.D.s in university laboratories (in university or CNRS permanent posts), in industry and in government agencies are nearly equal and total more than $90 \%$ of the yearly flow. Few people go to secondary school teaching and a very few are unemployed (i.e. take more than a few months to get a job). Engineering Ph.D.s have only a slightly larger proportion going to industry and a smaller fraction to university laboratories. The inflow into university laboratories has been stabilized since 1975 by a yearly increase of $3 \%$ of the CNRS staff (i.e. about $1 \%$ of the total teaching and research staff of the university + CNRS system), while recruitment into university posts has dwindled to negligible amounts in physics, and kept very low in engineering. Recruitment by government agencies such as those for Atomic Energy, Aeronautics, the Electricity Board, Telecommunications... has been notable ever since their development after the war. The flow into industry is mostly into large companies or their subsidiaries, often into their research laboratories for a period of five years before promotion into non-research activities. Starting with the development of the present system of Ph.D.s in the late fifties, the flow into industry developed mainly in the late seventies; indeed a lack of Ph.D.s has now developed in some specific fields such as microelectronics and materials science.

2. - In the United Kingdom, the situation is known for a majority of the holders of Ph.D.s with grants from the national Science and Engineering Research Council. It seems to be rather similar to the French with a somewhat reduced role for government agencies and a larger share of Ph.D.s staying in the universities $140 \%$ in physics). But real employment begins later in the universities, and only $11 \%$ of the physics and engineering Ph.D.s from 1980 were employed in the universities at the end of that year. Nevertheless in the late '70s, the recruitment situation in the British universities was generally more favourable than on the Continent. For example, more than $4 \%$ of the total number of university teachers were recruited in 1978. This was not primarily due to an inflation in the number of posts $(0.4 \%)$, but to retirement $(1.1 \%)$ made possible by the age structure of the teaching staff, the "brain drain" $(0.8 \%)$, departures for industry or govern- ment agencies $(0.4 \%$ each)... The new policy of the British government, to reduce the actual number of teaching posts in all universities, will probably result in a freeze in recruitment of young people over the next few years.

3. - I have unfortunately no recent study of employment of young scientific Ph.D.s in the Federal Republic of Germany. A long tradition of contact between universities and industry explains the important flow of scientific Ph.D.s to industry, which had somewhat decreased during the university expansion in the early '70s, but seemed to develop strongly again in the late 70 s. This has prevented any significant unemployment, despite the quasi-saturation of university posts. It is of some interest to compare this situation with that in the US and in Japan.

4. - In the United States, throughout the seventies, the percentage of US physics Ph.D.s staying in the university system was consistently bigger than $40 \%$ in physics and about $30 \%$ in engineering. The proportion going to industry was $50 \%$ in engineering but only $20 \%$ in physics, with about $10 \%$ of physics and engineering going into Federal or State agencies. Unemployment of young Ph.D.s was again minimal. Moreover, the general trend in recent years has been that industry has progressively switched its recruitment in engineering to masters. It is also worthwhile pointing out that four out of every five physics Ph.D.s who stayed in the university after their Ph.D. stay permanently in the university and college system (but not in one university!).

Thus, in the US, the major employment sector for physics Ph.D.s las well as for Ph.D.s as a whole) and an important one for engineering Ph.D.s is the university system. This has been made possible only through a systematic policy of inflation of the teaching personnel by the universities, at a general rate of $4.5 \%$ per year in the second half of the seventies $3.5 \%$ in permanent posts) although retirement rates will not reach a significant level until 1985 or even the '90s.

The reason for the somewhat reduced rate of industry recruitment in the US, as compared with the early seventies and with European countries, might be related to the higher age at which the Ph.D. is obtained. As stressed in the recent report of the EPS Erice Conference on the training of Ph.D.s. * industry, at least in Europe, seems to prefer to recruit mostly relatively young Ph.D.s, with a doctorate obtained in three years, thus typically below 26-27 years old. This allows a promotion from their first employment loften in industrial laboratories for large firms) to other activities at an age below 32 . This reasoning

- Copies of the Proceedings are available at the EPS Secretariat, price Sw.Fr. 40.-. 
does not, of course, include the small trickle of confirmed research people, of typically $30-35$ years, recruited by industry to set up research groups in new fields of activity.

5. - This point seems confirmed by an analysis of the situation in Japan. In 1980 after their three year Ph.D. course, only $44 \%$ found a job in natural sciences and $66 \%$ in engineering (in both cases, a quarter of the total in universities and colleges). The remaining Ph.D. students end their $\mathrm{Ph} . \mathrm{D}$. on the average, in one to two years more, and are thus around $28-29$ years old. No statistics are available on their employment, but it is clearly difficult, with few university posts and an industry which prefers recruiting masters to these older Ph.D.s. In physics, where 200-250 Ph.D.s have been formed yearly in recent years, universities take about 80 and industry few. It is then no surprise if about one third of all Ph.D.s formed since 1965 are apparently without employment.

\section{Conclusion}

From this very sketchy description, it can be seen that:

The rate of production of Ph.D.s as a function of population, is comparable in developed countries (except Japan).

Industry is a very important sector of possible employment, for physics as well as for engineering but, especially in countries like France or Japan where people do not change their employer easily, Ph.D.s must be young to find a job.

A minimal inflow of scientific Ph.D.s into university laboratories has been obtained until now in most countries, by various means; however, its importance for the well-being of the universities and the problem posed by the general lack of normal retirements until the ' 90 s have not always been sufficiently appreciated.

Government agencies, when developed, have been a preferential and rather stable sector of recruitment.

Finally secondary school teaching appears as a very minimal outlet for physics and engineering Ph.D.s; this is certainly a major weakness of the present situation.

\section{REFERENCES}

Statistics on yearly flows and stocks of Ph.D.s are given by the national Ministries of Education. Cf. also for FRG, reports by Central Bureau of Statistics, Wiesbaden and by Wissenschaftsrat (Empfehlungen und Stellungsnahmen 1980), for US, reports by the National Research Council, National Academy of Sciences, Washington (1978: Science, engineering and humanities doctorates in the Uniton States, 1977 profile: 1979: Summary Report 1978: Doctorate recipients from United States Universities:

1979: Non faculty doctcral research staff in science and engineering in United States universities).

Statistics on employment of Ph.D.s are given - in France by an 'Enquête sur le devenir pro-

\section{Twente University of Technology}

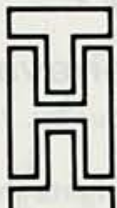

$A$ vacancy exists in the

DEPARTMENTS OF ELECTRICAL

ENGINEERING and APPLIED

PHYSICS of Twente University

of Technology for a

\section{full professorship}

in the Materials Science of Transducers Group which is part of both above mentioned

Departments.

The group participates in the activities of the Sensors and Actuators Research Unit of the Department of Electrical Engineering.

The research carried out by the group is principally involved with the development of materials for use in transducers (sensors and actuators), applicable in the field of information technology. Particularly the atomic fysical, chemical structural and (micro) technological aspects of materials science are subject of research. Work is also being carried out on the practical realization of these transducers.

\section{Duties}

The professorship carries the following responsibilities:

- to take part in the educational assignments of the group

- to contribute to the research-program

- to participate in processes of management, executive and policy matters concerned with education, research and personnel management.

\section{Requirements}

It is expected that the candidate is willing to participate in the current research program which is concentrated on thin magnetic films for use in magnetic transducers and is also capable of introducing new research projects of the material science of transducers for example IC-compatible transducers.

The candidate should have expertise and be interested in materials applicable for transducers especially in the fields of atomic and chemical structures and micro-technology.

It is also expected that the candidate will have knowledge and show interest in various fields of transducer applications.

The candidate should be able to provide the necessary inspiration and leadership in this multidisciplinary group in both educational and research duties. Good teaching ability is required.

\section{Information}

Enquiries should be made and information obtained from the Chairman of the Appointment Committee, Professor D. Bosman, tel. 053-893506.

Applicants for this position as well asthose who wish to direct the attention of the Committee to suitable candidates are requested to apply to or inform the Director of the Department of Electrical Engineering, Mr. A.G.N.M. Ploegmakers,

P.O. Box 217, 7500 AE Enschede, The Netherlands.

fessionnel des docteurs de spécialité: Physique', Association B. Gregory, 53 Rue de Turbigo, Paris $3^{e}(1978)$ and by unpublished analyses by the Association, by the Ministry of Education and the Ministry of Research.

- in Great Britain by enquiries on Science and Engineering Research Council Ph.D.s grants.

- in the US, by the studies mentioned above.
- in Japan, by studies published by the Ministry of Education.

A comparison of the various doctorates in science has been made by the 'Association $\mathrm{Na}$ tionale des docteurs ès Sciences', 16 Rue C. Bernard, Paris $5^{\mathrm{e}}$ : Etude sommaire comparative des diplômes universitaires scientifiques dans divers pays industrialisés (January 1980). 